\title{
Serum uric acid levels in psoriatic arthritis
}

\author{
JOHN R. LAMBERT AND V. WRIGHT \\ From The Rheumatism Research Unit, University Department of Medicine, General Infirmary, Leeds, and \\ Royal Bath Hospital, Harrogate
}

SUMMARY Serum uric acid levels were determined in patients with psoriatic arthritis on and offw medication, with rheumatoid arthritis on no medication likely to alter serum values, and in patientso with uncomplicated psoriasis. Values in males were higher than those in females. A larger prevalence? of values above the normal range were seen in males with psoriatic arthritis on uncontrolled ${ }^{\omega}$ medication $(13.5 \%)$ and in males with rheumatoid arthritis $(12 \%)$ than in the other groups. The means for both these groups were around the midpoints of the normal range. These findings suggest that hyperuricaemia is not a common characteristic of psoriatic arthritis.

Hyperuricaemia has been generally accepted as a frequent accompaniment of psoriasis and psoriatic arthritis. This association was first noted by Herrmann et al. (1930), who reported levels of uric acid above the upper limit of normal in 44 of 140 patients with psoriasis, especially in those with arthritis. Other authors reported similar findings (Steinberg et al., 1951; Tickner and Mier, 1960; Baumann and Jillson, 1960; Eisen and Seegmiller, 1961; Beveridge and Lawson, 1967; Pokorny and Resl, 1968; Solanet and Shulman, 1972). The prevalence of hyperuricaemia varied in these series from 21 to $50 \%$, the increase being more marked in males and in patients with arthritis. Eisen and Seegmiller (1961) found correlation of the serum uric acid level with the extent of skin involvement, and it has been postulated that the hyperuricaemia results from increased purine synthesis from the rapid epidermal cell turnover. However, their work with radioactively labelled glycine showed a pattern of turnover resembling primary rather than secondary gout.

Further evidence for the association was reported by Kaplan and Klatskin (1960) who described 3 patients with psoriasis, gout, and sarcoidosis. However, Lea et al. (1958) found no difference between the values of 19 psoriatic patients and controls. Schattenkirchner (1970) found no increase in the frequency of raised serum uric acid levels in psoriatic arthritis compared with seronegative chronic polyarthritis, and Little et al. (1975) found that in patients with severe psoriasis, with or without arthritis, the mean serum uric acid levels were

Accepted for publication August 19, 1976

Correspondence to Dr. J. R. Lambert, Rheumatism Research Unit, 36 Clarendon Road, Leeds LS2 9PJ in the middle of their normal range. A careful studyळ was undertaken of our patients to try to resolve these $\vec{c}$ conflicting reports.

\section{Materials and methods}

The study consisted of three parts. In the first plasma uric acid levels were estimated in $115^{\circ}$ patients ( 52 men, 63 women) with psoriatic arthritis fulfilling the criteria of Moll and Wright (1973). No흘 account was taken of medication. Values were 3 compared with the laboratory range of normal.

In the second part of the study uric acid levels. were measured on a group of 45 patients (13 men, 32 women) with psoriatic arthritis who had received only paracetamol for at least the preceding week. Values were compared with those obtained in $73{ }^{\circ}$ patients with uncomplicated psoriasis $(33 \mathrm{men}, 409$ women) and in 48 patients with rheumatoid arthritis (17 men, 31 women) receiving no medication known? to alter plasma uric acid levels.

In the third part of the study the characteristics of patients with hyperuricaemia were studied in more detail with particular attention to skin, nail, and joint changes. The extent of skin involvement was assessed by the rule of nine's (Evans et al., 1952), in which the surface of the body is divided into 11 areas? assumed to be $9 \%$ of the total body area, the genitals being assessed as the remaining $1 \%$. The arthritis was graded as mild (involvement of less than four joints with no loss of function), moderate (involve $\frac{0}{T}$ ment of less than four joints with deformity and/or loss of function, or involvement of many joints with only slight impairment of function), or severe (marked deformity and disability). 
Plasma uric acid was measured by the AutoAnalyser sodium tungstate method (Technicon Methodology N-13a) modified by substituting sodium carbonate for sodium cyanide. The laboratory range of normal values at Leeds is $0 \cdot 20-0.45$ $\mathrm{mmol} / 1$ for males and $\mathbf{0} \cdot 14-0.38 \mathrm{mmol} / 1$ for females (Cook et al., 1970).

\section{Results}

PART I

Fig. 1 gives the values obtained in 115 patients with psoriatic arthritis. The distribution in both sexes is roughly gaussian, though there is weighting towards higher values in males. 7 of the 52 men (13.5\%) and 3 of the 63 women $(5 \%)$ had levels above the quoted normal range. The mean value for females was 0.25 $\mathrm{mmol} / \mathrm{l}$, which is at approximately the midpoint of the normal range $(0.26 \mathrm{mmol} / \mathrm{l})$. This value is considerably lower than the mean value of males at $0.35 \mathrm{mmol} / 1$, which is also at roughly the midpoint of their normal range $(0.33 \mathrm{mmol} / \mathrm{l})$.

\section{PART II}

Fig. 2 shows the values of serum uric acid obtained in 43 patients with psoriatic arthritis who had received only paracetamol for at least the preceding week. Only one of 13 men $(7.5 \%)$ and 2 of 32 women $(6 \%)$ had values above normal. The mean value for females is similar at $0.26 \mathrm{mmol} / \mathrm{l}$, but that of males has fallen to $0.29 \mathrm{mmol} / \mathrm{l}$, a significant decrease $(P<0 \cdot 025$ : Student's ' $t$ ' test $)$.

In Fig. 3 the values obtained in 48 patients with rheumatoid arthritis, and no psoriasis, are shown. No females but 2 of 17 males $(12 \%)$ had values above normal. The mean value for females $(0.22 \mathrm{mmol} / \mathrm{l})$ was lower than that found in psoriatic arthritis on any treatment $(0.25 \mathrm{mmol} / 1 ; \mathrm{P}<0.01)$ or on paracetamol only $(0.26 \mathrm{mmol} / 1 ; \mathrm{P}<0.01)$.
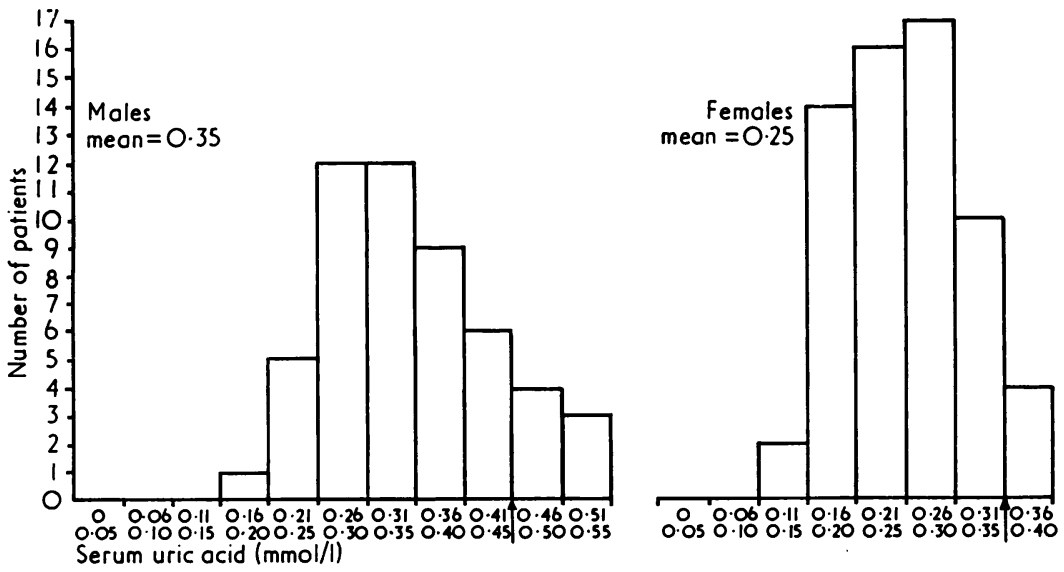

Fig. 1 Serum uric acid values in patients with psoriatic arthritis. Conversion: SI to traditional units-Serum uric acid: $1 \mathrm{mmol} / \mathrm{l} \approx 16.8$ $\mathrm{mg} / 100 \mathrm{ml}$. Arrows indicate upper limit of normal range.
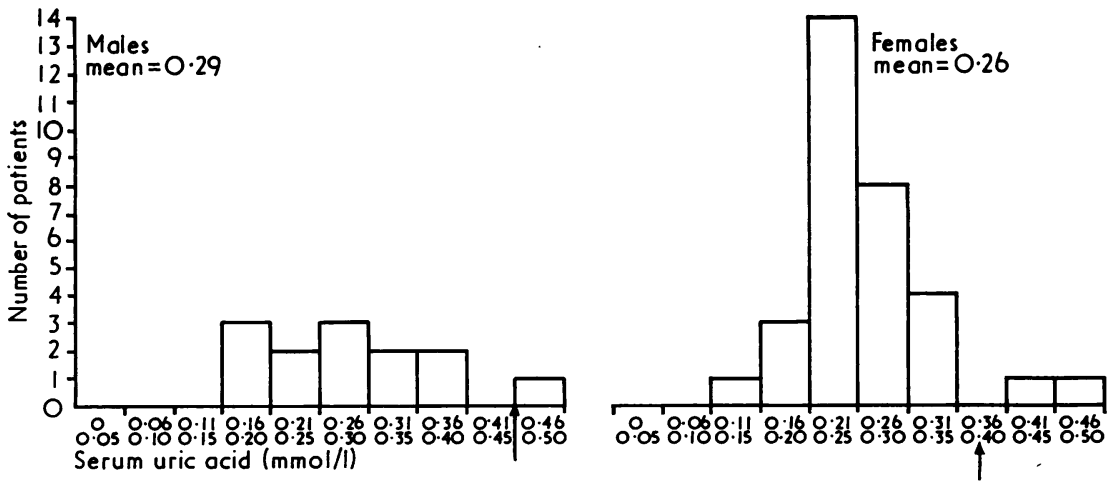

Fig. 2 Serum uric acid values in patient with psoriatic arthritis on paracetamol only. 
The values in 73 patients with uncomplicated psoriasis are shown in Fig. 4. None of the 33 males or $\mathbf{4 0}$ females had values above the normal range. The mean value for males $(0.29 \mathrm{mmol} / \mathrm{l})$ was the same as found in patients with psoriatic arthritis on paracetamol, being lower than that found in males with rheumatoid arthritis $(0.34 \mathrm{mmol} / \mathrm{l} ; \mathrm{P}<0.005)$ or in males with psoriatic arthritis on medication $(0.35 \mathrm{mmol} / 1 ; \mathrm{P}<0.0005)$. The mean value for females $(0.23 \mathrm{mmol} / \mathrm{l})$ was less than that for patients with psoriatic arthritis on any treatment $(0.25$ $\mathrm{mmol} / \mathrm{l}, \mathrm{P}<0.05)$ or on paracetamol only $(0.26$ $\mathrm{mmol} / \mathrm{l}, \mathrm{P}<0.025)$, but was similar to that found in females with rheumatoid arthritis $(0.22 \mathrm{mmol} / \mathrm{l})$.

\section{PART III}

The table compares the clinical characteristics of male psoriatic arthritis patients with hyperuricaemia with those of male psoriatic arthritis with normal values. The mean age at review and duration of arthritis were less in those with raised uric acid levels, though these differences were not significant.
There were no differences in the prevalence of nait changes or extent of psoriasis. There was a tenden $\overline{x y}$ for the arthritis to be less severe with hyperuricaemia though the difference was not significant.

Table Clinical characteristics of males with psoriatic arthritis and hyperuricaemia contrasted with those with normal values

\begin{tabular}{|c|c|c|}
\hline & $\begin{array}{l}\text { Patients with } \\
\text { hyperuricaemia }\end{array}$ & $\begin{array}{l}\text { Patients with } \\
\text { normal uric a }\end{array}$ \\
\hline Mean age at review (yr) & 48 & 52 \\
\hline Mean age at onset of arthritis (yr) & 42 & 41 \\
\hline Mean duration of arthritis (yr) & 6 & 11 \\
\hline Mean age at onset of psoriasis (yr) & 36 & 39 \\
\hline Mean duration of psoriasis (yr) & 12 & 13 \\
\hline Prevalence of nail changes $(\%)$ & 86 & 85 \\
\hline \multicolumn{3}{|l|}{ Severity of psoriasis $(\%)$} \\
\hline$<10 \%$ & 86 & 87 \\
\hline $10-20 \%$ & $\mathbf{0}$ & 4 \\
\hline$>20 \%$ & 14 & 9 \\
\hline \multicolumn{3}{|l|}{ Severity of arthritis ( $\%)$} \\
\hline Mild & 86 & 49 \\
\hline Moderate & 14 & 36 \\
\hline Severe & $\mathbf{0}$ & 15 \\
\hline
\end{tabular}

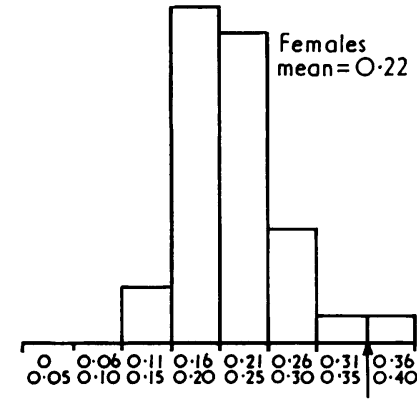

Serum uric ocid (mmol/l)
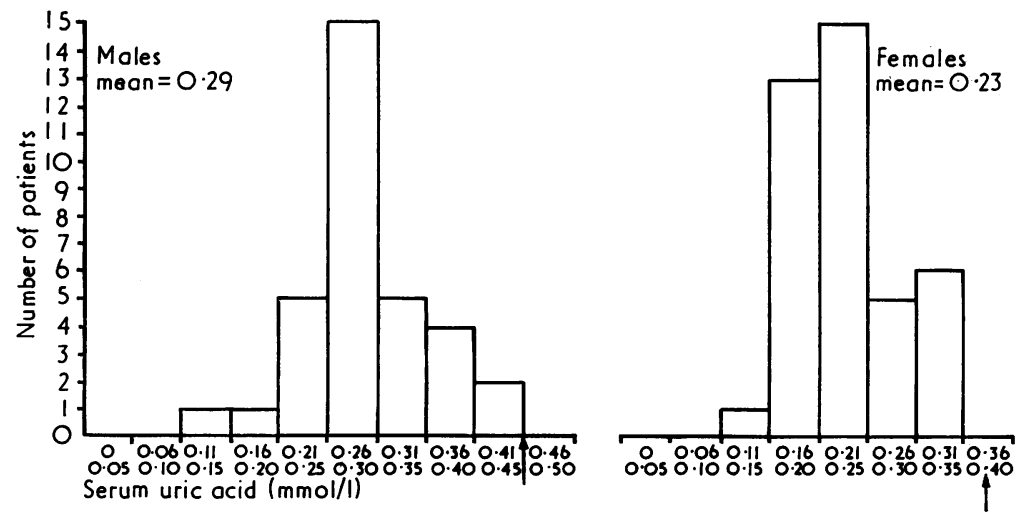

Fig. 3 Serum uric acid value in patients with rheumatoid arthritis.

Fig. 4 Serum uric acid value in patients with uncomplicated psoriasis. 


\section{Discussion}

The values obtained for serum uric acid in this study do not suggest that hyperuricaemia is a common finding in psoriatic arthritis, though they do show that there is some weighting of the distribution in favour of the higher values, especially in males. It is known that drugs can alter the values. Phenylbutazone blocks the proximal tubular reabsorption, leading to hypouricaemia, while aspirin (low dose) blocks distal tubular secretion producing hyperuricaemia. It is therefore of interest that the mean levels are the same for those female patients with psoriatic arthritis on paracetamol only and thosc on anti-inflammatory drugs. However, the value for male patients is lower in the group receiving paracetamol only.

Eisen and Seegmiller (1961) postulated that the rise in serum uric acid levels in patients with psoriasis was due to the increased cell turnover in the skin. However, none of our patients with uncomplicated psoriasis had raised values, and the mean value in males was less than that found in patients with rheumatoid arthritis, but no psoriasis. Mean values for patients with rheumatoid arthritis were as high as those found in psoriatic arthritis in males and higher than those found in uncomplicated psoriasis. This suggests that hyperuricaemia is not a characteristic of psoriasis or psoriatic arthritis.

We gratefully acknowledge the help of the staff of the chemical pathology laboratory, and discussions with Dr. R. B. Payne, Consultant Chemical Pathologist and Senior Clinical Lecturer.

\section{References}

Baumann, R. R., and Jillson, O. F. (1960). Hyperuricaemia and psoriasis. Journal of Investigative Dermatology, 36, 105-107.

Beveridge, G. W., and Lawson, A. A. H. (1967). Serum uric acid in psoriasis and arthritis. Scottish Medical Journal, 12, 21-27.

Cook, M. G., Levell, M. J., and Payne, R. B. (1970). A method for deriving normal ranges from laboratory specimens applied to uric acid in males. Journal of Clinical Pathology, 23, 778-780.

Eisen, A. Z., and Seegmiller, J. E. (1961). Uric acid metabolism in psoriasis. Journal of Clinical Investigation, 40, 1486-1494.

Evans, E. I., Purnell, O. J., Robinett, P. W., Batchelor, A., and Martin, M. (1952). Fluid and electrolyte requirements in severe burns. Annals of Surgery, 135, 804-815.

Herrmann, F. (1930). Harnsäureuntersuchungen bei Psoriasis. Archiv für Dermatologie und Syphilis, 161, 114-126.

Kaplan, H., and Klatskin, G. (1960). Sarcoidosis, psoriasis and gout: syndrome or coincidence? Journal if Biology and Medicine, 32, 335-352.

Lea, W. A., Curtis, A. C., and Bernstein, I. A. (1958). Serum uric acid levels in psoriasis. Journal of Investigative Dermatology, 31, 269-271.

Little, H., Harvie, J. N., and Lester, R. S. (1975). Psoriatic arthritis in severe psoriasis. Canadian Medical Association Journal, 112, 317-319.

Moll, J. M. H., and Wright, V. (1973). Psoriatic arthritis. Seminars in Arthritis and Rheumatism, 3, 55-78.

Pokorny, M., and Resl, V. (1968). Psoriasis and factors affecting the level of uricaemia. Acta Universitatis Carolinae. Medica, 14, 71-74.

Schattenkirchner, M. (1970). The symptomatology of arthritis psoriatica. Medizinische Klinik, 65, 29-30.

Solanet, P., and Shulman, L. (1972). Uricaemia in psoriasis. Archivos Argentinos de Reumatologia, 35, 1-3.

Steinberg, A. G., Becker, S. W., Fitzpatrick, T. B., and Kierland, R. R. (1951). A genetic and statistical study of psoriasis. American Journal of Human Genetics, 3, 267-281.

Tickner, A., and Mier, P. D. (1960). Serum cholesterol, uric acid, and proteins in psoriasis. British Journal of Dermatology, 72, 131-137. 